\title{
The Amsterdam Model for Control of Tattoo Parlours and Businesses
}

\section{Thijs Veenstra}

National Institute for Public Health and the Environment, Amsterdam, The Netherlands

\section{Abstract}

In the early 1980s, an outbreak of hepatitis B in Amsterdam stood at the start of the development of the first hygiene guidelines for tattooists in The Netherlands. Ever since, infection control in tattoo practice has continued to prove its importance as tattoo-related outbreaks of infectious diseases have continued to be reported in Europe. Furthermore, the act of tattooing includes breaking the skin barrier but is performed by professionals who are not medically trained. The Ministry of Health has now implemented uniform regulations that apply to professionals who perform tattooing and apply permanent make-up. These regulations include hygiene guidelines that were developed by the National Institute for Public Health and the Environment in cooperation with representatives of the tattooing associations. The guidelines contain a list of requirements, including for the studio interior, the cleanness of the studio, the safe use of permitted equipment and products, sterilization methods, and the information provid-
\end{abstract}

ed to the customer. A permit may be granted after an inspection by the local health service, during which the act of tattooing has to be performed. It is now estimated that over $95 \%$ of all tattoos in The Netherlands were obtained at one of the almost 900 licensed studios. Reports of complications are generally low in number. We suggest that uniform European hygiene guidelines would further contribute to the safety of tattooing.

(c) 2015 S. Karger AG, Basel

\section{The Amsterdam Model}

Infection control in tattoo studios is important. Over the past three decades, preliminary regulation in Amsterdam has grown into an effective national policy. Currently, tattoo practice in The Netherlands is subject to national hygiene guidelines that are created by tattooist organizations and infection-control professionals. 


\section{Hygiene in the Early 1980s}

In the early 1980s, an outbreak of hepatitis B among eight American soldiers stood at the start of regulated practice in The Netherlands. The outbreak alerted the public health service of Amsterdam to bad hygienic conditions in a vast and growing number of tattoo shops in the city when investigation of this outbreak revealed a tattoo studio with extremely unhygienic conditions [1]. The findings included reusing needles, testing needles on the tattooist's skin, and cleaning the client's skin with water that was previously used to rinse another person's tattoo. A survey among tattoo studios indicated that similar conditions were found in several other tattoo studios. Aware of the urgent need for regulation of tattooing practice, the public health service set up a preliminary guideline for tattoo parlours. In cooperation with a known local tattoo artist, ten 'golden rules' for infection prevention in tattoo studios were formulated [2].

After these ten golden rules were established, the local government applied local regulations to tattoo practice. This made it possible to enforce the regulations when a health risk was identified. Health inspectors were authorized to access the premises of registered studios at all times and to issue a warning when unacceptable conditions were identified. In The Netherlands, the city of Amsterdam gained a reputation for keeping a close eye on hygienic practices in tattoo studios.

\section{Aim for Regulated Hygienic Practice}

The act of tattooing is actually very similar to nursing or medical activities that should only be carried out by trained professionals. With tattooing, the natural skin barrier is broken, making the skin vulnerable to invasion by micro-organisms via needles, ink, or contact with contaminated materials or fluids before the skin has healed. Of course, using safe ink, with an absence of micro- biological contamination when leaving the manufacturer, is an important standard. There is, however, a variety of activities prior to the actual act of tattooing that may lead to the contamination of ink. These activities may be as simple as opening the bottle and touching the nozzle or as complicated as bacterial growth in bottles of diluted ink that have been used for too long. The process of tattooing consists of a chain of activities that are vulnerable to errors [3]. A sterile working field can be compromised by a lack of hand hygiene or ineffective disinfection of, for instance, the tattoo machine, after which bacteria may be introduced onto the skin by contact with the skin during tattooing. Furthermore, unprofessional use of a steam sterilizer will lead to the use of unsterile materials as safe materials.

Unlike training for health care workers, there is no universal professional education for tattoo artists that covers all aspects needed for safe practice. This does not mean that every artist poses a health risk when tattooing without hygiene guidelines, but it leaves room for serious errors, as we have seen in the last few years, when errors in practice led to infections in clients [4]. In The Netherlands, initiatives by tattooist organizations to introduce universal professional education have still not led to a sufficient training program. The increasing number of consumers who choose to get a tattoo has also led to a rise in the number of persons at risk for tattoo-related infections. Consumers have little knowledge of infection control in tattooing practice and rely on the artist's professional skills [5]. This means that there is a need for a system that ensures the safety of tattoo artists' clients by regulating the practice of tattooists and the use of safe products.

\section{Hygiene Guidelines}

More elaborate guidelines were established in The Netherlands in 1987 [Bronnen van Joy]. Several organizations contributed to these guidelines, 
including organizations for tattooists, infectioncontrol specialists from the public health service, dermatologists, and health inspectors. Since then, the guidelines have been subject to revision every 4 years, which makes it possible to update the guidelines with new insights as well as with information about new activities in tattooing practice that need specific safety measures. The current guidelines [6] date from 2014 and are divided into several chapters. The main chapter relates directly to the act of placing a tattoo. This includes general measures such as sufficient hand hygiene and personal protective equipment, e.g. gloves that meet international standards. The chapter provides principles for safe practice with regard to cleaning instruments, inks, and needles; using sterile packaging before and during tattooing; safely disposing of contaminated materials and sharps; and providing instructions for safe aftercare. The second chapter covers the cleaning, disinfection, and sterilization of surfaces and materials, which are categorized based on whether they penetrate or have contact with the skin and whether they can be contaminated by blood or ink from a used needle. This chapter provides principles for carrying out these activities in a professional way. A special chapter is dedicated to building, equipping, and furnishing the area. An orderly, noncramped working space with well-cleanable surfaces is the main required condition. Tattooing must be carried out separately from other activities and from waiting clients. A hand-washing facility must be within close range and has to be located in the same room. The last chapter contains information to be provided to the client about correct aftercare and about seeking the right medical assistance in the case of a complication.

\section{National Legislation}

In 2007, national legislation was established by the Dutch Ministry of Health, Welfare, and Sports. It contained regulations for tattooing ac- tivities as well as for permanent make-up and piercing and was based on the Amsterdam model. In addition to hygiene guidelines, age limits were set for clients getting a tattoo. In the national program, an owner of a studio must obtain a license for using tattooing materials. The license has to be renewed every 3 years. In order to obtain a license, the holder must request an inspection by the public health service, during which all aspects of the guidelines are assessed. Furthermore, the artist has to demonstrate the act of tattooing as well as preparations to show his/her ability to work according to the hygienic principles. When not all aspects are in accordance with the guidelines, a re-inspection is issued before the shop may operate. During the 3 -year period of the license, authorities may visit a studio unannounced to ensure that the guidelines are still being followed. Failing to comply with the hygiene guidelines may lead to an official warning, and failing to improve practice may result in the license being withdrawn. Performing commercial tattooing activities without a license is now illegal and may lead to a EUR 1,500 penalty.

In addition to the legislation, the government assigned the National Centre for Public Health and the Environment to establishing a public website for consumers that provides information about getting a tattoo safely [7]. The website mainly consists of a database containing all currently licensed studios. Furthermore, it provides information about tattooing and health, assessing hygiene in a studio, proper aftercare, how to act when a complication occurs, and where to submit complaints.

\section{Effects}

Since 2007, the number of licensed tattoo shops in The Netherlands has increased almost threefold (fig. 1). It is difficult to measure the exact effect of hygienic practice and legislation, as 
Fig. 1. Number of licensed tattoo studios in The Netherlands.

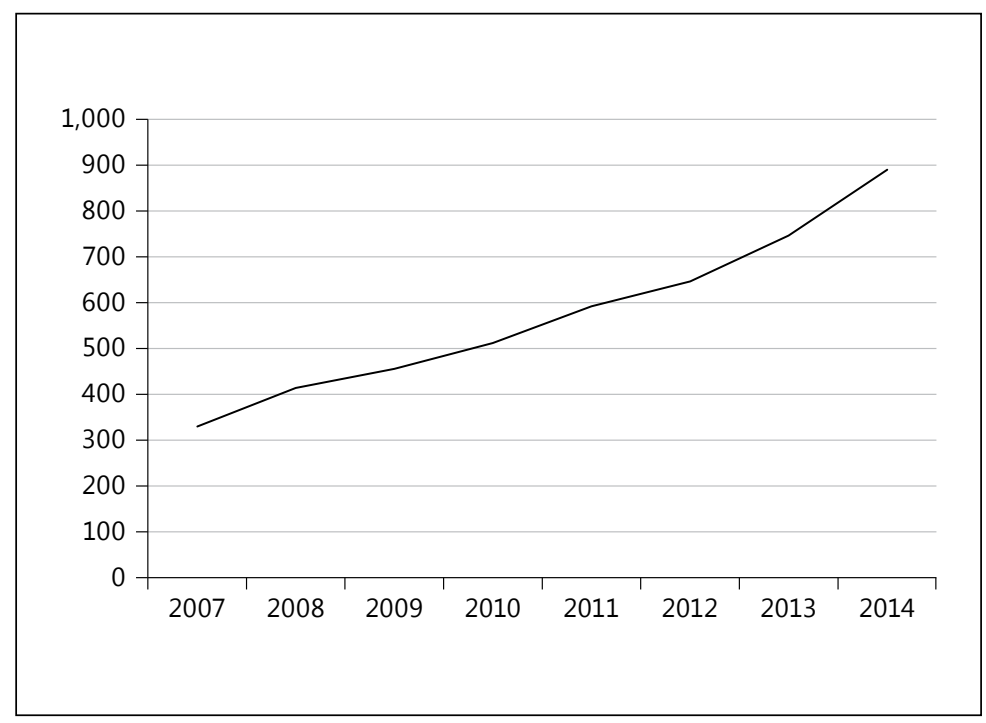

complications are not registered. Unfortunately, serious complications such as hepatitis B infection are often difficult to relate to a specific cause. In 2009, the authorities in The Netherlands ordered a survey of 292 persons who had recently gotten a tattoo [8]. Based on the survey, it was estimated that $95 \%$ of the tattoos had been obtained at a licensed studio. Only $2 \%$ reported a complicated healing process. It is remarkable that five out of the seven people who reported complications after getting a tattoo had gotten their tattoo at an unlicensed studio. Unfortunately, the study lacked baseline data. A study in 2009 showed no increased prevalence of hepatitis B and C among tattoo artists in Amsterdam [9]. However, this study was not intended to measure the effects of the regulation on the number of hepatitis $\mathrm{B}$ and $\mathrm{C}$ infections.

Resistance to the legislation exists among a number of Dutch tattoo artists. Their main counterargument is the fact that illegal activities (kitchen-table scratchers) are still reported. Some artists claim that staff from foreign countries are unfamiliar with the Dutch guidelines and have difficulties in complying. Furthermore, tattoo artists as well as consumers argue that the fact that the license solely covers safety and does not cover the quality provided by the tattoo artist is confusing to some.

\section{A Uniform Model}

The Amsterdam model is an example of an effective way to regulate the practice of tattooing. Still, a licensing system has both benefits and limitations, and there are other types of legislation that can be considered for implementation to ensure that tattooists provide safe practice. The importance of universally implementing hygiene guidelines has been acknowledged, as the act of tattooing is not limited by national borders. Many artists operate in more than one country, and many consumers get their tattoo abroad. The current diversity in legislation and guidelines does not support compliance, as artists need to adapt to different instructions when operating abroad. Universal European guidelines would contribute to compliance with hygiene guidelines. 


\section{References}

1 Worp J, Boonstra A, Coutinho R-A, van den Hoek J-A-R: Tattooing, permanent make-up and piercing in Amsterdam; guidelines, legislation and monitoring. Euro Surveill 2006;11:34-36.

2 Worp J, Boonstra A: Evaluation Report of Tattoo and Piercing Studios in Amsterdam (in Dutch). Public Health Service of Amsterdam, 1999.

3 LeBlanc P-M, Hollinger K-A, Klontz $\mathrm{K}-\mathrm{C}$ : Tattoo ink-related infections awareness, diagnosis, reporting, and prevention. New Engl J Med 2012;367: 985-987.
4 Conaglen P-D, Laurenson I-F, Sergeant A, Thorn S-N, Rayner A, Stevenson J: Systematic review of tattoo-associated skin infection with rapidly growing mycobacteria and public health investigation of a cluster in Scotland, 2010. Euro Surveill 2013;18:20553.

$>5$ Quaranta A, Napoli C, Fasano F, Montagna $\mathrm{C}$, Caggiano $\mathrm{G}$, Montagna $\mathrm{M}-\mathrm{T}$ : Body piercing and tattoos: a survey on young adults' knowledge of the risks and practices in body art. BMC Public Health 2011;11:774.
6 Veenstra T: Tattoo Hygiene Guidelines. The Netherlands, National Institute for Public Health and the Environment, 2014.

7 Veilig tatoeëren en piercen. http://www. veiligtatoeeren.nl/ (accessed November 15, 2014).

8 Zweers J, Grimmius T: Report, Evaluation of Legislation Tattoo and Piercing (in Dutch). Research voor Beleid, 2011.

-9 Urbanus A-T, van den Hoek A, Boonstra A, van Houdt R, de Bruijn L-J, Heijman T, Coutinho R-A, Prins M: People with multiple tattoos and/or piercings are not at increased risk for HBV or HCV in The Netherlands. PLoS One 2011;6:e24736. 